\title{
Phenotypic Characterization and Random Amplified Polymorphic DNA (RAPD) analysis of Pasteurella multocida isolated from Korean Pigs
}

\author{
Ki-Eun LEE ${ }^{1}$, Hye-Young JEOUNG ${ }^{1}$, Ji-Youn LEE ${ }^{1}$, Myoung-Heon LEE ${ }^{1}$, Hwan-Won CHOI ${ }^{2)}$, Kyung-Soo CHANG ${ }^{3)}$, \\ Young-Hee $\mathrm{OH}^{4}$ and Dong-Jun $\mathrm{AN}^{1}$ * \\ 1) Animal, Plant and Fisheries Quarantine and Inspection Agency, Anyang, Gyeonggi-do, 430-824, South Korea \\ 2) ChoongAng Vaccine Laboratories, Daejon, 305-348, South Korea \\ 3) Catholic University of Pusan, Busan, 609-757, South Korea \\ ${ }^{4}$ Seoul metropolitan Government Research Institute of Public Health and Environment, Gwacheon, Gyeonggi-do, 427-070, South \\ Korea
}

(Received 9 September 2011/Accepted 29 November 2011/Published online in J-STAGE 13 December 2011)

ABStract. Pasteurella multocida causes various respiratory disease symptoms in pigs, including atrophic rhinitis and pneumonia. In the present study, 69 strains of $P$. multocida were isolated from 443 pigs with respiratory clinical symptoms at 182 farms located throughout South Korea from 2009 to 2010. A multiplex capsular PCR typing assay revealed that 69 strains of $P$. multocida isolated in this study had the biosynthetic locus of the capsules of either serogroup A (47 strains, 68.1\%) or serogroup D (22 strains, 31.9\%). The 22 strains positive for serogroup D-specific primers were divided into four clusters and the 47 strains positive for serogroup A-specific primers were divided into 12 clusters according to the results of Random Amplified Polymorphic DNA (RAPD) analysis. P. multocida strains in the present study were susceptible to most of the antimicrobial agents used. An analysis of antimicrobial resistance and virulence gene pattern combined with RAPD indicated that a certain P. multocida strain appeared to be genetically identical, implying the persistence of the strain within a single farm.

KEY WORDS: antimicrobial, Pasteurella multocida, RAPD, serogroup, swine.

doi: 10.1292/jvms.11-0418; J. Vet. Med. Sci. 74(5): 567-573, 2012

Pasteurella multocida is a pathogen that induces respiratory disease with symptoms such as cough, bronchial pneumonia, and severe breathing difficulty in pigs. Chronic respiratory $P$. multocida infection results in a characteristic dry cough and delayed growth, whereas acute infection can bring about death in 5 to 10 days [9]. P. multocida is divided into five serogroups (A, B, D, E, and F) based on their capsular polysaccharide. Serogroups A and D lead to major pig lung disease, and if they are combined with other pathogens, such as Mycoplasma hyopneumoniae or pseudorabies virus, they can increase the severity of pneumonia lesions $[2,4,7,10]$. P. multocida infections are transmitted by droplet or contact.

In 2003, P. multocida was isolated from lung lesions in $10.3 \%$ of pigs with pneumonia in South Korea. The strains isolated were sensitive to most antimicrobial agents, including ampicillin, ceftiofur and enrofloxacin, but had low-level resistance to neomycin $[9,11,18]$.

Other studies of P. multocida have investigated pathogenic factors such as capsular polysaccharide, virulence factors, lipopolysaccharide, and outer membrane protein $[6,14,16]$. These characteristics have also been analyzed by ribotyping, single-primer PCR, and Random Amplified

\footnotetext{
*Correspondence To: An, D.-J., Research Planning Division, Animal, Plant and Fisheries Quarantine and Inspection Agency, Anyang, Gyeonggi-do 430-824, South Korea. e-mail: andj67@korea.kr
}

(C)2012 The Japanese Society of Veterinary Science
Polymorphic DNA (RAPD) PCR [5, 12, 15]. The merit of the RAPD-PCR assay is that it is simple and requires less time to process than other methods of restriction endonuclease analysis $[12,15]$. RAPD-PCR analysis for characterization of $P$. multocida has yielded reproducible and reliable results in comparison with other analytical methods such as whole cell protein, outer membrane protein, serotyping, and restriction endonuclease analyses [15]. An ornithological study showed that 66 strains of $P$. multocida isolated from birds could be easily and quickly categorized into 18 groups through RAPD-PCR [12]. P. multocida has been isolated from many pigs with respiratory disease, but no major studies characterizing the strains, nor any major epidemiological studies, have been undertaken for isolates from South Korea.

The purpose of this study was to investigate the distribution of serogroups and virulence genes, and determine the antimicrobial susceptibility of $P$. multocida isolated from pigs with respiratory disease in South Korea from 2009 to 2010. In addition, RAPD-PCR was performed to clarify and compare the genetic characteristics of $P$. multocida.

\section{MATERIALS AND METHODS}

Isolation and identification of P. multocida: Lung samples were collected from pigs with respiratory diseases, such as pneumonia and breathing difficulties by ChoonAng Vaccine Laboratories of the animal appraisal organization. A total of 443 pig lung samples were obtained from 182 pig farms in nine provinces (Gyeonggi, Gang- 
won, Chungbuk, Chungnam, Jeonbuk, Jeonnam, Gyeongbuk, Gyeongnam, and Jeju) throughout South Korea from January 2009 to November 2010. Among the farms where lung samples were collected, pigs with respiratory clinical symptoms were again detected after several months. All lung samples were collected under aseptic conditions and were inoculated on to brain heart infusion (BHI) agar (Difco, Beckton, Dickinson and Co., Sparks, MD, U.S.A.) containing $5 \%$ sheep blood and incubated for $24 \mathrm{hr}$ at $37^{\circ} \mathrm{C}$. The suspected colonies (mucoid, non-hemolytic colonies) were tested with MacConkey agar (Difco, Beckton, Dickinson and Co.), gram stain, and biochemistry (oxidase, indole, and urease).

Preparation of $P$. multocida genomic DNA: The isolated P. multocida were inoculated into BHI broth (Difco, Beckton, Dickinson and Co.) and cultured for $18 \mathrm{hr}$. P. multocida genomic DNA was extracted using the Genomic DNA Extraction Kit (INTRON, Gyeonggi, South Korea) and was stored at $-20^{\circ} \mathrm{C}$ until use.

Detection of P. multocida by PCR: The KMT1 gene (common gene of $P$. multocida capsule) of $P$. multocida was amplified with a primer set (5'-ATCCGCTATTTACCCAGTGG-3' and '5'-GCTGTAAACGAACTCGCCAC- $3^{\prime}$ ) as previously described [16]. The PCR conditions consisted of $5 \mathrm{~min}$ at $95^{\circ} \mathrm{C}$, followed by 30 cycles of $30 \mathrm{sec}$ at $95^{\circ} \mathrm{C}, 30 \mathrm{sec}$ at $55^{\circ} \mathrm{C}$, and $30 \mathrm{sec}$ at $72^{\circ} \mathrm{C}$. A DNA fragment of $460 \mathrm{bp}$ was expected.

Genotyping of capsular polysaccharide gene by multiplex PCR: To distinguish capsular polysaccharide, multiplex-PCR was performed as previously described [16]. The multiplex-PCR was performed by $5 \mathrm{~min}$ at $95^{\circ} \mathrm{C}, 30$ cycles of $30 \mathrm{sec}$ at $95^{\circ} \mathrm{C}, 30 \mathrm{sec}$ at $55^{\circ} \mathrm{C}$, and $30 \mathrm{sec}$ at $72^{\circ} \mathrm{C}$. The amplification fragments, anticipated to be 1,044 bp (serogroup A), 760 bp (serogroup B), 657 bp (serogroup D), 511 bp (serogroup E), and 851 bp (serogroup F) in length, were visualized on a $1 \%$ agarose gel.

Detection of virulence genes by PCR: The detection of virulence genes ( $h s f-1, p f h A, h g b B$, tox $A$, and $n a n B$ ) was carried out using a PCR assay as previously described [3]. Three of the genes, $p f h A, h g b B$ and tox $A$, were amplified with 35 cycles of $45 \mathrm{sec}$ at $94^{\circ} \mathrm{C}, 50 \mathrm{sec}$ at $54^{\circ} \mathrm{C}$, and $50 \mathrm{sec}$ at $72^{\circ} \mathrm{C}$. The two other genes, $n a n B$ and $h s f-1$, were amplified with 30 cycles of $30 \mathrm{sec}$ at $94^{\circ} \mathrm{C}, 30 \mathrm{sec}$ at $56^{\circ} \mathrm{C}$, and 30 sec at $72^{\circ} \mathrm{C}$. The amplification fragments, anticipated to be 846 bp (toxA), 654 bp (hsf-1), 550 bp (nanB), 499 bp (hgbB) and $275 \mathrm{bp}(p f h A)$ in length, were visualized using gel electrophoresis on a $2 \%$ agarose gel.

Antimicrobial susceptibility testing: Minimal inhibitory concentrasions (MICs) were determined using the standard broth dilution methods according to Clinical Laboratory Standards Institute (CLSI) guideline (M31-A3) for ampicillin, penicillin, ceftiofur, danofloxacin, enrofloxacin, spectinomycin, sulphadimethoxine, gentamicin, neomycin, tilmicosin, tulathromycin, florfenicol, tiamulin, chlortetracycline, and oxytetracycline. As a control strain, Escherichia coli(ATCC 25922) was used.

Random amplified polymorphic DNA (RAPD) PCR: The primer used for RAPD-PCR was MM13 (5'-GAGGGTG-
GNGGNTCT-3'), as previously described [15]. The PCR conditions consisted of 30 cycles of $30 \mathrm{sec}$ at $95^{\circ} \mathrm{C}, 30 \mathrm{sec}$ at $42^{\circ} \mathrm{C}$, and $30 \mathrm{sec}$ at $72^{\circ} \mathrm{C}$. The products were subjected to electrophoresis at 100 volts in $2 \%$ agarose gel, and DNA bands in the gel were stained with ethidium bromide. DNA banding patterns were analyzed using BioNumerics software (Applied Maths) to calculate Dice coefficients of correlation and to generate a dendrogram using the unweighted pair group method of arithmetic averages (UPGMA) clustering.

\section{RESULTS}

Isolation of P. multocida: P. multocida was isolated from 64 of the 182 farms from which pig specimens were collected. The total number of positive farms from which $P$. multocida was isolated in each region during the study period was as follows: Gyeongbuk $(n=30)$, Chungnam $(n=10)$, Gyeongnam $(n=8)$, Gyeonggi $(n=6)$, Jeonbuk $(n=5)$ and other regions $(n=5)$ (Table 1$)$. Because pigs with respiratory symptoms were detected after 4 months in 4 farms (farms $\mathrm{A}$ and D in Gyeongbuk, farm B in Jeonnam, and farm C in Gyeongnam), the animals were sampled again to isolate $P$. mutocida(Table 4). P. multocida was isolated from $19.4 \%$ $(38 / 196)$ of the pigs examined in 2009 and $12.6 \%(31 / 247)$ of the pigs examined in 2010 (Table 1).

Genotyping of the capsular polysaccharide gene by multiplex PCR: Of the 38 strains isolated in 2009, 24 strains $(63.2 \%)$ carried the biosynthetic locus of the capsule of serogroup A and 14 (36.8\%) carried that of serogroup D. Among the 31 strains isolated in 2010, the biosynthetic locus of the capsules of serogroups A and D were detected in $23(74.2 \%)$ and 8 strains $(25.8 \%)$, respectively (Table 1$)$.

Distribution of virulence genes: The distributions of five virulence genes ( $h s f-1, p f h A, h g b B$, tox $A$, and nanB) among $P$. multicida strains isolated in this study are shown in Table 2. The $h s f-1, h g b B$ (adhesins) and $\operatorname{nanB}$ (sialidase) virulence genes were each present in $>80 \%$ of $P$. multocida strains having the locus of the capsule of serogroup D and the toxA gene was found in only two of the strains. The virulence genes in P. multocida isolated from the same farm at intervals of several months are presented in Table 4.

Antimicrobial susceptibility: Antimicrobial susceptibility testing of $P$. multocida showed that there was no strain resistant to the five antimicrobials tested (ceftiofur, tilmicosin, tulathromycin, chlortetracycline, and oxytetracycline), although against the other antimicrobials a low level of resistance was shown (Table 3). The MIC ranges for isolated strains between 2009 and 2010 were somewhat different. Comparing MIC90 $(\mu \mathrm{g} / \mathrm{m} l)$, that of danofloxacin decreased from $>1 \mu \mathrm{g} / \mathrm{m} l$ in 2009 to $\leq 0.12 \mu \mathrm{g} / \mathrm{m} l$ in 2010 , and that of enrofloxacin decreased from $1 \mu \mathrm{g} / \mathrm{m} l$ in 2009 to $0.25 \mu \mathrm{g} / \mathrm{m} l$ in 2010. On the other hand, the resistance rate for tiamulin increased from $42.10 \%$ in 2009 to $74.19 \%$ in 2010 . The antimicrobial resistance patterns for $P$. multocida isolated from the same farm at intervals of several months are presented in Table 4.

RAPD analysis: The DNA banding pattern for the P. mul- 
Table 1. Number of farms and number of pigs from which P. multocida was isolated during 2009-2010

\begin{tabular}{|c|c|c|c|c|c|c|c|c|}
\hline \multirow{3}{*}{ Province } & \multicolumn{4}{|c|}{2009} & \multicolumn{4}{|c|}{2010} \\
\hline & \multirow{2}{*}{$\begin{array}{l}\text { No.of farm tested } \\
\text { (No.of positive } \\
\text { farm) }\end{array}$} & \multirow{2}{*}{$\begin{array}{l}\text { No.of pig tested } \\
\text { (No.of positive } \\
\text { pigs) }\end{array}$} & \multicolumn{2}{|c|}{$\begin{array}{l}\text { No. of strains with } \\
\text { serogroup* }\end{array}$} & \multirow{2}{*}{$\begin{array}{l}\text { No.of farm tested } \\
\text { (No.of positive } \\
\text { farm) }\end{array}$} & \multirow{2}{*}{$\begin{array}{l}\text { No.of pig tested } \\
\text { (No.of positive } \\
\text { pigs) }\end{array}$} & \multicolumn{2}{|c|}{$\begin{array}{c}\text { No. of strains } \\
\text { with serogroup* }\end{array}$} \\
\hline & & & $\mathrm{A}$ & $\mathrm{D}$ & & & $\mathrm{A}$ & $\mathrm{D}$ \\
\hline Gyeonggi & $7(4)$ & $12(4)$ & 4 & 0 & $11(2)$ & $13(2)$ & 2 & 0 \\
\hline Gangwon & $0(0)$ & $0(0)$ & 0 & 0 & $1(0)$ & $3(0)$ & 0 & 0 \\
\hline Chungbuk & $1(0)$ & $2(0)$ & 0 & 0 & $3(1)$ & $13(1)$ & 1 & 0 \\
\hline Chungnam & $8(4)$ & 17 (4) & 2 & 2 & $33(6)$ & $60(6)$ & 4 & 2 \\
\hline Jeonbuk & $6(2)$ & $23(2)$ & 1 & 1 & $6(3)$ & $17(3)$ & 1 & 2 \\
\hline Jeonnam & $3(2)$ & $9(3)$ & 3 & 0 & $10(1)$ & $23(1)$ & 0 & 1 \\
\hline Gyeongbuk & $32(18)$ & 103 (18) & 10 & 8 & $30(12)$ & 80 (13) & 11 & 2 \\
\hline Gyeongnam & $11(3)$ & $29(6)$ & 4 & 2 & $19(5)$ & $38(5)$ & 4 & 1 \\
\hline Jeju & $1(1)$ & $1(1)$ & 0 & 1 & $0(0)$ & $0(0)$ & 0 & 0 \\
\hline Total & $69(34)$ & $196(38)$ & 24 & 14 & $113(30)$ & 247 (31) & 23 & 8 \\
\hline
\end{tabular}

*The biosynthetic locus of the capsule of serogroups A and D were detected by a multiplex PCR analysis.

Table 2. Virulence gene distribution in P. multocida strains

\begin{tabular}{lllccc}
\hline \multirow{2}{*}{ Gene function } & \multirow{2}{*}{ Gene } & & \multicolumn{2}{c}{ No. of strains with serogroup* } & \multirow{2}{*}{ Total (n=69) } \\
\cline { 3 - 5 } & & & $\mathrm{A}$ & $\mathrm{D}$ & \\
\hline Adhesins & $h s f-1$ & Autotransporter adhesion & $1(2.1 \%)$ & $20(90.9 \%)$ & $21(30.4 \%)$ \\
Adhesins & $p f h-A$ & Filamentous hemagglutinin & $13(27.6 \%)$ & $0(0.0 \%)$ & $13(18.8 \%)$ \\
Iron acquisition & $h g b B$ & Hemoglobin-binding protein & $33(70.2 \%)$ & $21(95.4 \%)$ & $54(78.3 \%)$ \\
Toxins & toxA & Dermonecrotic toxin & $0(0.0 \%)$ & $2(9.1 \%)$ & $2(2.9 \%)$ \\
Sialidase & nanB & $\begin{array}{l}\text { Outer membrane associated protein, an autotrans } \\
\text { portor protein }\end{array}$ & $18(38.3 \%)$ & $18(81.8 \%)$ & $36(52.2 \%)$ \\
& & & & \\
\hline
\end{tabular}

*The biosynthetic locus of the capsule of serogroups A and D were detected by a multiplex PCR analysis.

Table 3. Minimal Inhibitory Concentration (MIC) and resistance rates of P. multocida isolated from pig during 2009-2010

\begin{tabular}{|c|c|c|c|c|c|c|c|}
\hline \multirow[b]{2}{*}{ Antimicrobial agents } & \multirow[b]{2}{*}{ Breakpoint } & \multicolumn{3}{|c|}{$2009(\mathrm{n}=38)$} & \multicolumn{3}{|c|}{$2010(n=31)$} \\
\hline & & $\begin{array}{c}\text { MIC range } \\
(\mu \mathrm{g} / \mathrm{m} l)\end{array}$ & $\begin{array}{c}\mathrm{MIC}_{90} \\
(\mu \mathrm{g} / \mathrm{m} l) \\
\end{array}$ & $\begin{array}{c}\text { Resistance } \\
(\%)\end{array}$ & $\begin{array}{c}\text { MIC range } \\
(\mu \mathrm{g} / \mathrm{m} l)\end{array}$ & $\begin{array}{c}\mathrm{MIC}_{90} \\
(\mu \mathrm{g} / \mathrm{m} l)\end{array}$ & $\begin{array}{c}\text { Resistance } \\
(\%)\end{array}$ \\
\hline Ampicillin & $-*$ & $\leq 0.25-16$ & 4 & - & $\leq 0.25->16$ & $\leq 0.25$ & - \\
\hline Penicillin & $-*$ & $\leq 0.12->8$ & $>8$ & - & $\leq 0.12->8$ & 2 & - \\
\hline Ceftiofur & $\geq 8$ & $\leq 0.25-1$ & $\leq 0.25$ & 0.0 & $\leq 0.25$ & $\leq 0.25$ & 0.0 \\
\hline Danofloxacin & $\geq 0.25$ & $\leq 0.12->1$ & $>1$ & 26.3 & $\leq 0.12->1$ & $\leq 0.12$ & 3.2 \\
\hline Enrofloxacin & $\geq 2$ & $\leq 0.12-2$ & 1 & 7.9 & $\leq 0.12->2$ & 0.25 & 3.2 \\
\hline Spectinomycin & $-*$ & $\leq 8->64$ & $>64$ & - & $16->64$ & 32 & - \\
\hline Sulphadimethoxine & $-*$ & $256->256$ & $>256$ & - & $256->256$ & $>256$ & - \\
\hline Gentamicin & $\geq 16$ & $\leq 1->16$ & $>16$ & 18.4 & $\leq 1->16$ & 8 & 6.5 \\
\hline Neomycin & $-*$ & $\leq 4->32$ & $>32$ & - & $\leq 4-16$ & 8 & - \\
\hline Tilmicosin & $\geq 32$ & $\leq 4-16$ & 8 & 0.0 & $\leq 4-16$ & 8 & 0.0 \\
\hline Tulathromycin & $\geq 64$ & $\leq 1-8$ & 4 & 0.0 & $\leq 1-4$ & 2 & 0.0 \\
\hline Florfenicol & $\geq 8$ & $\leq 0.25->8$ & 8 & 10.5 & $\leq 0.25->8$ & 8 & 16.5 \\
\hline Tiamulin & $\geq 32$ & $\leq 4->32$ & 32 & 42.1 & $8->32$ & $>32$ & 74.2 \\
\hline Chlortetracycline & $\geq 16$ & $\leq 0.5-8$ & 2 & 0.0 & $\leq 0.5-8$ & 4 & 0.0 \\
\hline Oxytetracycline & $\geq 16$ & $\leq 0.5-8$ & 8 & 0.0 & $\leq 0.5-8$ & 8 & 0.0 \\
\hline
\end{tabular}

* There is no antimicrobial breakpoint in the Clinical Laboratory Standard Institute (CLSI) guideline.

tocida strains amplified using the MMI3 primer is indicated in Figs. 1 and 2. The 22 strains with the biosynthetic locus of the capsule of serogroup D strains were classified into four clusters based on $80 \%$ similarity in the RAPD banding pattern (Fig. 1). Three of the strains, KVCC-BA1100179, KVCC-BA1100188, and KVCC-BA1100213, were isolated from farm A in Gyeongbuk province in April, August, and December, 2009, respectively. The remaining 19 strains were isolated from different farms. The 47 strains with the locus of the capsule of serogroup A strains were divided into 12 clusters (Fig. 2). Following strains with the locus of the capsule of serogroup A isolated from the same farm 
Table 4. Random Amplified Polymorphic DNA (RAPD), antimicrobial resistance and viruence gene pattern for P. multocida isolates from pigs of four farms

\begin{tabular}{|c|c|c|c|c|c|c|c|c|c|c|}
\hline \multirow{2}{*}{ Province } & \multirow{2}{*}{ Date } & \multirow{2}{*}{ Strain No. } & \multirow{2}{*}{ Serogroup* } & \multirow{2}{*}{ RADP pattern } & \multirow{2}{*}{$\begin{array}{l}\text { Antimicrobial } \\
\text { resistance pattern** }\end{array}$} & \multicolumn{5}{|c|}{ Viruence gene } \\
\hline & & & & & & $h s f-1$ & $p f h A$ & $h g b B$ & $\operatorname{tox} A$ & $\operatorname{nan} B$ \\
\hline \multirow{3}{*}{$\begin{array}{c}\text { Farm A } \\
\text { (Gyeongbuk) }\end{array}$} & Apr 2009 & KVCC-BA1100179 & $\mathrm{D}$ & Cluster I & DAN-TIA & + & - & + & - & + \\
\hline & Aug 2009 & KVCC-BA1100188 & $\mathrm{D}$ & Cluster I & DAN-TIA & + & - & + & - & + \\
\hline & Dec 2009 & KVCC-BA1100213 & $\mathrm{D}$ & Cluster Ш & TIA & + & - & + & - & - \\
\hline \multirow{2}{*}{$\begin{array}{c}\text { Farm B } \\
\text { (Jeonnam) }\end{array}$} & Oct 2009 & KVCC-BA1100194 & $\mathrm{A}$ & Cluster I & DAN & - & - & + & - & + \\
\hline & Nov 2009 & KVCC-BA1100214 & $\mathrm{A}$ & Cluster XII & GEN & - & + & + & - & - \\
\hline \multirow{2}{*}{$\begin{array}{c}\text { Farm C } \\
\text { (Gyeongnam) }\end{array}$} & Apr 2010 & KVCC-BA1100221 & $\mathrm{A}$ & Cluster II & No resistance & - & + & + & - & - \\
\hline & Sep 2010 & KVCC-BA1100229 & A & Cluster II & No resistance & - & - & + & - & + \\
\hline \multirow{2}{*}{$\begin{array}{c}\text { Farm D } \\
\text { (Gyeongbuk) }\end{array}$} & Apr 2009 & KVCC-BA1100177 & $\mathrm{A}$ & Cluster VI & DAN & - & - & - & - & - \\
\hline & Aug 2009 & KVCC-BA1100190 & A & Cluster VI & DAN & - & - & - & - & - \\
\hline
\end{tabular}

${ }^{*}$ The biosynthetic locus of the capsule of serogroups A and D were detected by a multiplex PCR analysis.

** DAN, danofloxacin; TIA, tiamulin; GEN, gentamicin.

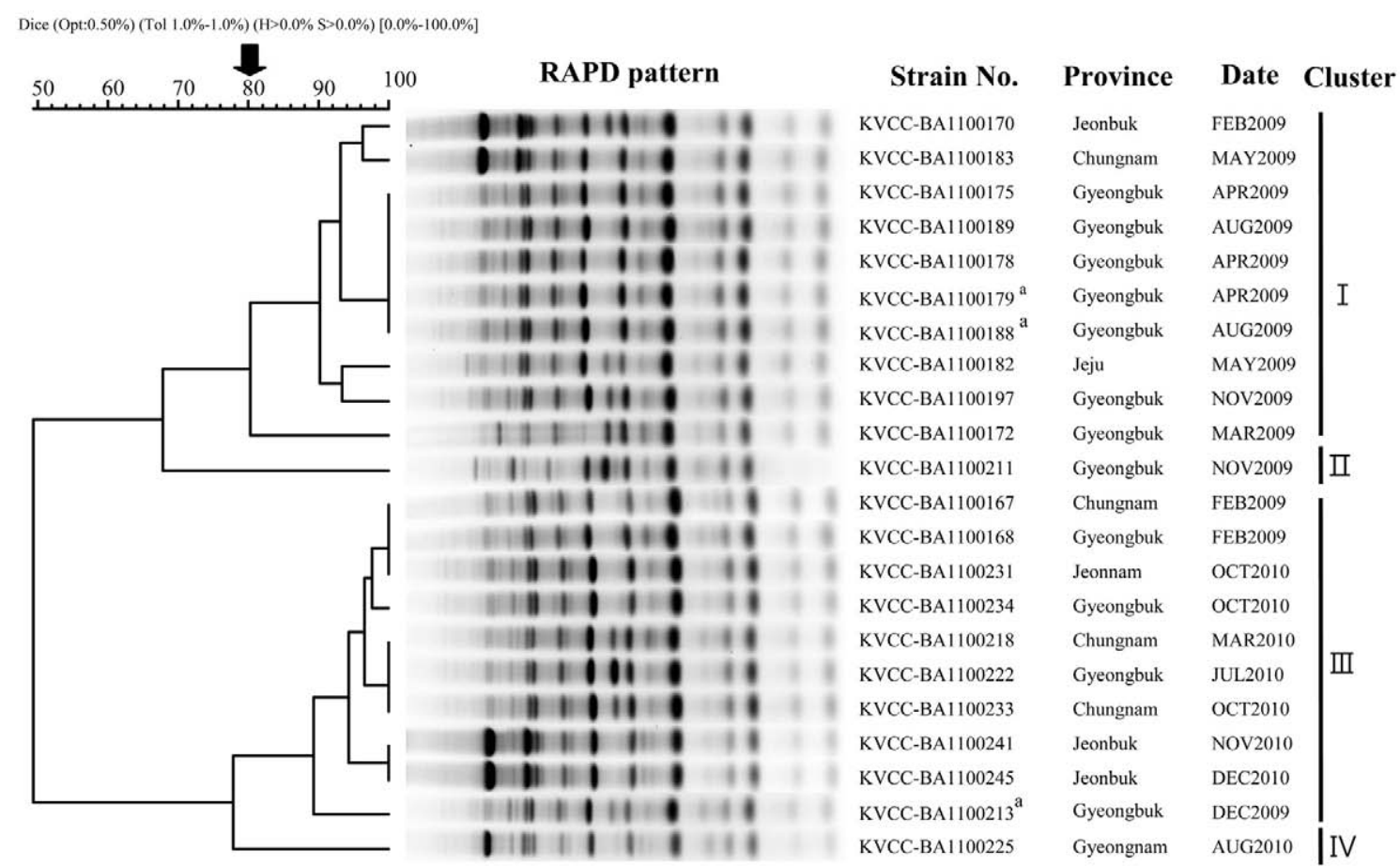

Fig. 1. RAPD profiles of P. multocida strains with the biosynthetic locus of the capsule of serogroup D that were analyzed using the BioNumerics program (Applied Maths) to generate a dendrogram based on the Dice coefficient. Twenty two strains were divided into four clusters at similar rate of $80 \%$. ${ }^{\text {a }}$ Strains isolated from farm A in Gyeongbuk.

at different times were classified into identical clusters: KVCC-BA1100221 (April, 2010) and KVCC-BA1100229 (September, 2010) from farm C in Gyeongnam, and KVCCBA1100177 (April, 2009) and KVCC-BA1100190 (August, 2009) from farm $D$ in Gyeongbuk. The remaining 43 strains were isolated from different farms.

\section{DISCUSSION}

The major serogroups of $P$. multocida that reproduce in the respiratory tract of pigs are $\mathrm{A}$ and $\mathrm{D}$ [14]. Of 80 strains of $P$. multocida isolated from slaughtered Korean pigs in 1994, 77 (96.3\%) were found to be serogroup A and the other three were serogroup D [1]. Of 91 strains isolated in 2009, 69 (75.8\%) were serogroup A and 22 (24.2\%) were serogroup D [13]. The majority (68.1\%) of the isolates from the present study carried the biosynthetic locus of the capsule of serogroup A, suggesting that serogroup A has been the most common cause of pig respiratory disease up to now. No pigs appeared to be coinfected with multiple 
Dice (Opt: $0.50 \%)$ (Tol 1.0\%-1.0\%) (H>0.0\% S>0.0\%) $[0.0 \%-100.0 \%]$

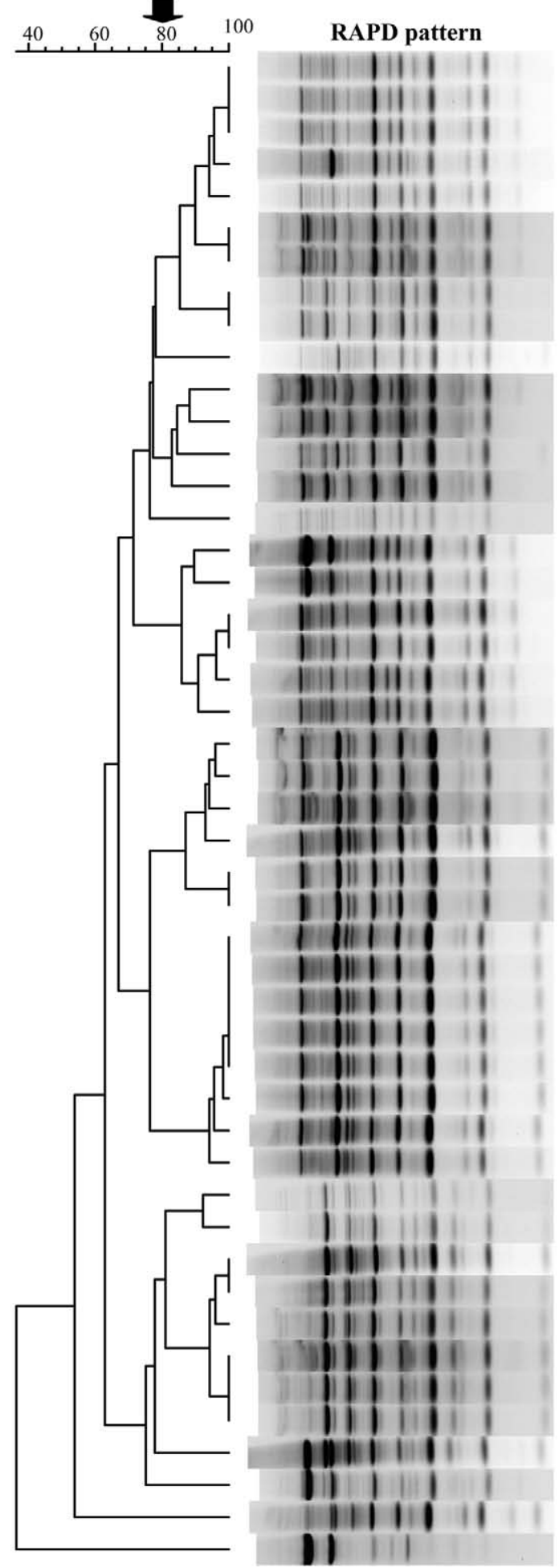

\begin{tabular}{|c|c|c|c|}
\hline Strain No. & Province & Date & Cluster \\
\hline VCC-BA1100195 & Gyeongbuk & NOV2009 & | \\
\hline VCC-BA1100196 & Gyeongbuk & NOV2009 & \\
\hline VCC-BA1100210 & Gyeongbuk & NOV2009 & \\
\hline KVCC-BA1100194 & Jeonnam & ОСТ2009 & \\
\hline VCC-BA1100212 & Jeonnam & NOV2009 & $\mathrm{T}$ \\
\hline VCC-BA1100236 & Gyeongbuk & NOV2010 & \\
\hline VCC-BA1100237 & Gyeongbuk & NOV2010 & \\
\hline CC-BA1100242 & Gyeongbuk & NOV2010 & \\
\hline /CC-BA1100243 & Gyoungbuk & NOV2010 & \\
\hline VCC-BA1100214 & Jeonnam & NOV2009 & XII \\
\hline VCC-BA1100229 & Gyeongnam & SEP2010 & \\
\hline VCC-BA1100230 & Gyeongbuk & OCT2010 & \\
\hline VCC-BA1100221 ${ }^{\mathrm{b}}$ & Gyeongnam & APR2010 & II \\
\hline VCC-BA1100232 & Gyeongbuk & OCT2010 & \\
\hline VVCC-BA1100216 & Chung & JAN2010 & |III \\
\hline VCC-BA1100173 & Gyeonggi & MAR2009 & \\
\hline VCC-BA1100191 & Gyeongbuk & SEP2009 & \\
\hline VVCC-BA1100171 & Chungnam & FEB2009 & IV \\
\hline KVCC-BA1100193 & Gyeonggi & ОСТ2009 & $1 \mathrm{IV}$ \\
\hline VCC-BA1100180 & Gyeongbuk & APR2009 & \\
\hline VCC-BA1100184 & Gyeongbuk & JUN2009 & \\
\hline VCC-BA1100226 & Gyeongnam & SEP2010 & \\
\hline VCC-BA1100238 & Chungnam & NOV2010 & \\
\hline KVCC-BA1100227 & Gyeongbuk & SEP2010 & $\mathrm{V}$ \\
\hline VCC-BA1100166 & Gyeongbuk & JAN2009 & \\
\hline VCC-BA1100217 & Gyeongnam & FEB2010 & \\
\hline VCC-BA1100220 & Chungnam & APR2010 & \\
\hline KVCC-BA1100177 & Gyeongbuk & APR2009 & \\
\hline KVCC-BA1100181 & Chungnam & MAY2009 & \\
\hline VCC-BA1100186 & Gyeongnam & JUL2009 & \\
\hline VCC-BA1100187 & Gyeonggi & JUL2009 & VI \\
\hline KVCC-BA1100190 & Gyeongbuk & AUG2009 & \\
\hline ECC-BA1100192 & Gyeonggi & SEP2009 & \\
\hline KVCC-BA1100174 & Gyeongbuk & MAR2009 & \\
\hline ECC-BA1100185 & Gyeongbuk & JUL2009 & \\
\hline VCC-BA1100215 & Jeonbuk & JAN2010 & \\
\hline KVCC-BA1100244 & Gyeongbuk & NOV2010 & \\
\hline KVCC-BA1100165 & Gyeongnam & JAN2009 & \\
\hline KVCC-BA1100219 & Chungnam & MAR2010 & \\
\hline KVCC-BA1100224 & Gyeongbuk & AUG2010 & VII \\
\hline VVCC-BA 1100228 & Chungbuk & SEP2010 & \\
\hline KVCC-BA1100235 & Chungnam & OCT2010 & \\
\hline CVCC-BA1100239 & Gyeonggi & NOV2010 & \\
\hline VCC-BA1100169 & Jeonbuk & FEB2009 & IVIII \\
\hline VCC-BA1100240 & Gyeonggi & NOV2010 & IIX \\
\hline VCC-BA1100176 & Gyeongbuk & APR2009 & IX \\
\hline VCC-BA1100223 & Gyeongbuk & AUG2010 & IXI \\
\hline
\end{tabular}

Fig. 2. RAPD profiles of P. multocida strains with the biosynthetic locus of the capsule of serogroup A that were analyzed using the BioNumerics program (Applied Maths) to generate a dendrogram based on the Dice coefficient. Forty seven strains were divided into eleven clusters at similar rate of $80 \%$. ${ }^{\text {a }}$ Strains isolated from farm B in Jeonnam; ${ }^{\mathrm{b}}$ strains isolated from farm $\mathrm{C}$ in Gyeongnam; ${ }^{\mathrm{c}}$ strains isolated from farm D in Gyeongbuk. 
strains with the locus of the capsule of serogroups A and D in the present study. Serious respiratory symptoms in pig may stem from the more pathogenic virulence factors ( $h s f$ 1 and $n a n B$ ) and the dermonecrotic toxin of serogroup D $[8,14]$. Therefore, ongoing observation of the pattern of pig respiratory disease is needed.

Antimicrobials that are used domestically for disease prevention and treatment purposes in livestock are administered by addition to feedstuff, but regulation concerning this type of use of antimicrobials is becoming more complicated. Since 2005, in order to prevent the over-use and misuse of antimicrobials and to increase the safety of livestock products, there has been a step-by-step decrease in the types of antimicrobials that are added to feedstuff. According to the Animal, Plant and Fisheries Quarantine and Inspection Agency (www.qia.go.kr), there were 11 types of antimicrobials that were permitted in feedstuff in South Korea up until recently.

A study of 87 strains of P. multocida isolated from Korean pigs between 1996 and 1997 showed resistance rates to ampicillin, enrofloxacin, gentamicin and trimethoprim/ sulfamethoxazole of $3.2 \%, 4.6 \%, 16.1 \%$ and $48.3 \%$, respectively [11]. In another study, 31 strains isolated in South Korea in 2003 also showed resistance to ampicillin, enrofloxacin, gentamicin, and trimethoprim/sulfamethoxazole, with resistance rates of $3.4 \%, 0 \%, 28.9 \%$, and $38.7 \%$, respectively, as well as to streptomycin, penicillin, and neomycin, indicating low susceptibility [9]. Antimicrobial susceptibility analysis in the present study yielded resistance rates in the isolated strains for both years $(2009 / 2010)$, as follows: ceftiofur $(0.0 \% / 0.0 \%)$, enrofloxacin $(15.8 \% / 3.2 \%)$, gentamicin $(28.9 \% / 19.3 \%)$, and chlortetracycline $(0 \% / 0 \%)$. These results were similar to rates of antimicrobial resistance reported previously [9, 11]. Interestingly, tiamulin exhibited a higher resistance rate in the 2010 isolates than in the 2009 isolates. Of 132 P. multocida strains isolated in Germany between 2002 and 2003, only $0.2 \%$ were found to be resistant to enrofloxacin [17], while the present study found a resistance rate of $15.8 \%$ for enrofloxacin. Another previous study reported that $P$. multocida showed 100\% susceptibility to quinolone antimicrobials such as enrofloxacin and norfloxacin [1]; however, data from research done after 1999 have shown resistance levels of $6-8 \%$. The addition of quinolone antimicrobials to feedstuff has been prohibited in South Korea since 2008, due to researchers' concerns.

Another paper found resistance rates in P. multocida strains isolated from China in 2009 to be $74.2 \%$ (trimethoprim/sulfamethoxazole), $65.2 \% \quad$ (chlortetracycline), $80.3 \%$ (clindamycin), 28.3\% (tilmicosin), and $13.7 \%$ (gentamicin) [14]. These resistance rates are far higher than those seen in strains isolated in South Korea and Europe. These high resistance rates seen in China are assumed to be due to the over-use and misuse of antimicrobials in feedstuff. In South Korea, the addition of antimicrobials to feedstuff has been totally prohibited since July 2011. In light of the new regulations, continuous observation for any change in antimicrobial susceptibility in strains isolated from livestock is warranted.

RAPD analysis results for 69 strains show that they can be divided into 16 different clusters. The five strains (KVCCBA1100175,-BA1100178,-BA1100179, -BA1100188, and -BA1100189) that carried the locus of the capsule of serogroup D had a similar rate of $100 \%$ in the RAPD dendrogram analysis. Among these, KVCC-BA1100179 (April, 2009) and KVCC-BA1100188 (August, 2009) strains were isolated from farm A in Gyeongbuk province and they appeared identical in antimicrobial resistance and virulence gene pattern. Also, KVCC-BA1100177 (April, 2009) and KVCC-BA1100190 (August, 2009), which belonged to cluster VI within the strains with the locus of the capsule of serogroup A, were collected on different dates from farm $\mathrm{D}$ in Gyeongbuk. The strains have identical antimicrobial resistance and virulence gene pattern, suggesting that persistence of identical strain within a single farm.

This study indicates that thorough disinfection and sterilization on pig farms will be necessary for the eradication of $P$. multocida in light of the prohibition of antimicrobials throughout South Korea.

ACKNOWLEDGMENT. We are grateful to ChoongAng Vaccine Laboratories for deposition of $P$. multocida isolated from pig.

\section{REFERENCES}

1. Ahn, B. C., Cho, K. H. and Kim, B. H. 1994. Studies on Pasteurella multocida isolated from pneumonic lungs of slaughter pigs. Korean. J. Vet. Res. 34: 511-516.

2. Amass, S. F., Clark, L. K., van Alstine, W. G., Bowersock, T. L., Murphy, D. A., Knox, K. E. and Albreqts, S. R. 1994. Interaction of Mycoplasma hyopneumoniae and Pasteurella multocida infections in swine. J. Am. Vet. Med. Assoc. 204: 102-107. [Medline]

3. Atashpaz, S., Shayegh, J. and Hejazi, M. S. 2009. Rapid virulence typing of Pasteurella multocida by multiplex-PCR. Res. Vet. Sci. 87: 355-357. [Medline] [CrossRef]

4. Carter, G. R. 1988. Serological classification of Pasteurella. Vet. Rec. 122: 311. [Medline] [CrossRef]

5. Dziva, F., Christensen, H., Van Leengoed, L. A. M. G., Mohan, K. and Olsen, J. E. 2004. Differentiation of Pasteurella multocida isolates from cases of atrophic rhinitis in pig from Zimbabwe by RAPD and ribotyping. Vet. Microbiol. 102: 117122. [Medline] [CrossRef]

6. Ewers, C., Lubke-Becker, A., Bethe, A., Kiebling, S., Filter, M. and Wieler, L. H. 2006. Virulence genotype of Pasteurella multocida strains isolated from different hosts with various disease status. Vet. Microbiol. 114: 304-317. [Medline] [CrossRef]

7. Fuentes, M. and Pijoan, C. 1986. Phagocytosis and killing of Pasteurella multocida by alveolar macrophages after infection with pseudorabies virus. Vet. Immunol. Immunopathol. 13: 165-172. [Medline] [CrossRef]

8. Harper, M., Boyce, J. D. and Adler, B. 2006. Pasteurella multocida pathogenesis: 125 years after Pasteur. FEM. Microbiol. Lett. 265: 1-10. [CrossRef]

9. Lee, W. W., Woo, B. G. and Lee, G. R. 2003. Isolation and antimicrobial susceptibility test of Pasteurella multocida from respiratory disorder piglets. Rep. Busan. Inst. Health Environ 
13: $142-150$.

10. Lichtensteiger, C. A., Steenbergen, S. M., Steenbergen, R. M., Lee, R. M., Polson, D. D. and Vimr, E. R. 1996. Direct PCR analysis for toxigenic Pasteurella multocida. J. Clin. Microbiol. 34: 3035-3039. [Medline]

11. Shin, N. A., Park, J. Y., Park, Y. H. and Yoo, H. S. 1999. Characteristics of Pasteurella multocida isolated from pneumonic lung lesions of swine: antimicrobial susceptibility, plasmid profile and distribution of toxA. Korean. J. Vet. Res 39: 10911098.

12. Shivachandra, S. B., Kumar, A. A. and Chaudhuri, P. 2007. Differentiation of avian Pasteurella multocida strains by single primer PCR. Vet. Res. Commun. 31: 941-949. [Medline] [CrossRef]

13. Sohn, J. H., Choi, S. K. and Cho, G. J. 2009. Capsular serogroups and toxA gene of Pasteurella multocida isolated from pneumonic lung lesions of swine. J. Vet. Clin. 26: 457-462.

14. Tang, X., Zhao, Z., Hu, J., Wu, B., Cai, X., He, Q. and Chen, H. 2009. Isolation, antimicrobial resistance, and virulence genes of Pasteurella multocida strains from swine in China. J. Clin. Microbiol. 47: 951-958. [Medline] [CrossRef]

15. Taylor, J. D., Fulton, R. W., Dabo, S. M., Lehenbauer, T. W. and Confer, A. W. 2010. Comparison of genotypic and phenotypic characterization methods for Pasteurella multocida isolates from fatal cases of bovine respiratory disease. J. Vet. Diagn. Invest. 22: 366-375. [Medline] [CrossRef]

16. Townsend, K. M., Boyce, J. D., Chung, J. Y., Frost, A. J. and Adler, B. 2001. Genetic organization of Pasteurella multocida cap loci and development of a multiplex capsular PCR typing system. J. Clin. Microbiol. 39: 924-929. [Medline] [CrossRef]

17. Wallmann, J. 2006. Monitoring of antimicrobial resistance in pathogenic bacteria from livestock animals. Int. J. Med. Microbiol. 296: 81-86. [Medline] [CrossRef]

18. Yoshimura, H., Ishimaru, M., Endoh, Y. S. and Kojima, A. 2001. Antimicrobial susceptibility of Pasteurella multocida isolated from cattle and pigs. J. Vet. Med. B Infect. Dis. Vet. Public Health 48: 555-560. [Medline] [CrossRef] 